\title{
Integrating Writing With Listening in EFL Class: A Systematic Review
}

\author{
${ }^{1}$ Mister Gidion Maru* \\ English Education Department, \\ Faculty of Arts and Language \\ Universitas Negeri Manado \\ Tondano, Indonesia \\ mrgidionmaru@unima.ac.id
}

\author{
${ }^{2}$ Chris Caesar Pikirang \\ Klabat University \\ Manado, Indonesia \\ pikirangchris68@gmail.com
}

\author{
${ }^{3}$ Nihta Liando \\ English Education Department, \\ Faculty of Arts and Language \\ Universitas Negeri Manado \\ Tondano, Indonesia \\ nihtaliando@unima.ac.id
}

\begin{abstract}
Writing is one of the vital skills in higher education life. It may determine academic achievement and mark language proficiency. This review aims at sharing of reports on examining the attempt to integrate writing with listening that has done in prior studies in the field of EFL or ESL class. material is an effort of combining two skills in the same time, therefore, hoping, by doing that would improve the students' skill in listening and writing. For the purpose of framing this review, the key search terms used to gain data were integrating writing skills" and "listening skill", "also "systematic review", and "English as a Foreign Language" or "EFL" also "English as a second language" or "ESL". The studies have been identified through popular electronic databases web site namely ERIC and Google Scholar particularly those appears in the first five screen show which each screen consists of ten relevant articles, resulted in fifty possible relevant ones. They are then identified and selected basis upon the main key search terms' the integration of writing and listening as prescribed in the inclusion and exclusion criteria: This systematic review provided a descriptive data on context, participants, aim, methods, and main outcomes applied in integrating writing and listening skills with their relevant activities such as listening diary and journal writing and then singing. This review also reveals that the lack of the number of studies related to the integration of the two skills. Yet, It challenges more studies focusing on different methods and strategy for better results, breakthroughs and recommendations.
\end{abstract}

\section{Keywords: Writing, Listening Integration, Systematic Review}

\section{INTRODUCTION}

Writing skill constitutes a vital competence in the higher education life. Besides it marks the acquisition of the targeted language for foreign language learners, writing skill implies the ability of comprehending ideas and thoughts, and the means of expressing and elaborating notions and insights as well. Writing is "tool for writer to convey his or her ideas, thoughts and feelings" [1]. That means that this particular skill is pivotal in language learning and communication. It relies upon the use of words, sentences, body paragraphs and even essays [1]. Hence, reference [2] believed that "having an ability to write in English is essential for students in the globalization era". This is not hyperbolic. Students' writing ability can be an access towards global interaction. The academic assignments and correspondence currently oblige writing proficiency. The writing product is considered being the product of mind and behavior. Reference [3] also pointed out that nowadays writing is a skill that cannot be separated from human's life; especially in academic field within which it is a must for students in university level to do writing. Papers, essays, notes, summaries and reviews as common tasks and assignments in college learning activities are all required in the forms of systematic writing. It poses the writing skill as one of the productive skills which prescribes learners to produce, construct and negotiate meaning on their own words within the targeted language rules, structure and vocabulary. Writing skill "allows language learners to demonstrate and produce knowledge and improve language learners' learning ability" [4]. At this point, in academic practices, writing skill serves also as the knowledge assessment instrument. The result of students' writing is treated as the reflection of the material absorption and knowledge elaboration. Teachers or lecturers evaluate the product based upon the writing rubric for technicality and mechanism, and knowledge depth for content and impact. In other words, writing skill is comprehensively essential for both students and teachers. It may act as the reflection of language competence for language learners in particular, and knowledge; critical and creative thinking, for students in general, and also as means of the assessment and evaluation for teachers. Regarding its complex nature, writing provides individuals with such skills as observation sensitivity, ability to analyze, ability to perceive, ability to express ideas, and the reflection of vocabulary, not to mention the cultural context awareness. These traits define writing to be in the line for assessment not simply for language skill but also critical thinking. On the other side, these make writing to be challenging subject for students. Reference [5], believed that "writing is the most difficult language skill. It requires high level of thinking abilities". That means that it is a blessing in disguise. The success of developing students' writing ability may lead to the success of academic purposes as to encourage critical thinking and communicative skills. Language fluency is acquired, 
knowledge is absorbed. Thus, It is essential to design writing material appropriately for students. It becomes vital to develop and integrate writing in EFL classroom as the ways to endorse the language and knowledge competence. It is further anticipative to the current modes of learning such as face to face learning, blended learning and online learning.

Integrating writing with listening can be an alternative. Listening is regarded as a perceptive skill that allows students to process the information. Listening skill had been defined by some researchers nowadays; "as a basic skill of language, listening is an essential process at interpretation surroundings. Listening, as writing, is "necessary in many cases such as school life, interfamilial communication Thanks to listening, people acquire comprehension skills and expressing themselves in all areas." [6]. Through listening skill, students can comprehend the meaning of words that being spoken and also will allow them to respond the speakers. Reference [7], believed that "listening is the process of decoding the audial input with the use of language"; They further argued that "while decoding the spoken language by perceiving it, the listener transforms the words within discourse into a mental representation to get the meaning via parsing." Similar to writing, listening may be stated as "one of the most important skills in English language learning" [8]. Hence, listening can be a skill that essential to students by that allowing them to perceive meanings of information, process them, and to respond them both written and spoken. This poses benefit and challenge of integrating writing and listening; skill to communicate and skill to decode; knowledge is processed and then produced. The development for material to adjust with these purposes seems to be bridged by carrying out a systematic review of the studies or experiences which are previously done in order to gain perspective and breakthroughs for EFL practices and later students' success in higher education world.

The current review tries to examine if there are any correlations by integrating writing and listening skill in a subject. Having searched and selected various online resources particularly articles within journal, there are three most relevant studies that researcher examined which range from 2015 and to 2019. The result of the study will be summarized in the table in the methodology section. Beside those three studies there were also some resources from several journals which range at the same year as the literature study to this systematic review. This review focuses upon the studies on integrating writing and listening skill in language learning to respond to the following adapted questions [9]:

1. Where the studies conducted?

2. Who were participants of the studies?

3. What were aims of these studies?

4. What methodology and methods were used?

5. What were the main findings?
6. What are the directions for future integrating writing and listening skill in language learning research?

\section{RESEARCH METHODS}

Systematic review is a valuable tool in collecting the critical scientific evidence necessary for developing evidence-based guidelines, making programmatic decisions, and guiding future research (Mullins, et al. 2014, as cited in reference [10]. Moreover, systematic review is the essential means for researchers for finding a fact for particular study, in this case, the integration of writing and listening in an EFL classroom. This systematic literature review involves the following steps which based on Hoang (2018):

1. Defining the questions and choosing keywords, inclusion and exclusion criteria and databases.

2. Carrying out the literature study.

3. Screening the references.

4. Assessing the quality.

5. Extracting the data into a summary table of information.

6. Synthesizing the studies to answer the research questions.

7. Writing up the report.

The objective of this review is addressed to examine studies related to the attempt to integrate writing and listening on language learning and to provide the results of the study as guided by the response toward the questions above. It is necessary to be acknowledged that in the process of review that it is found a proposition that a particular activity which designed properly would enhanced students' skill in writing and listening skill; for instance, the notions identified in the ideas of journal writing by reference [11] and listening diary by reference [12]. For the purpose of framing this review, the key search terms used to gain data were integrating writing skills" and "listening skill", "also "systematic review", and "English as a Foreign Language" or "EFL" also "English as a second language" or "ESL". The studies have been identified through popular electronic databases web site namely ERIC and Google Scholar particularly those appears in the first five screen show which each screen consists of ten relevant articles, resulted in fifty possible relevant ones. They are then identified and selected basis upon the main key search terms' the integration of writing and listening as prescribed in the following Inclusion criteria:

- Research that focused on writing and listening only

- Research that focused on the result of research result of writing and listening proficiency based on particular task

- Research that focused on whole full text journal that can be accessed online for free

- Academic publication from 2014 to 2019

Exclusion criteria:

- Literature focus on writing or listening only

Therefore, the researcher summarized up those reports into a summary table in the following label: (1) Context, (2) Participants, (3) Aim, (4) Methods, and (5) Main Outcomes. The collected information found was 
synthesized to answer the research questions. Finally, the criteria systematically selected only three most relevant articles that closely discusses the key search terms. Considering the significance, It implies the limited resources on the subjects as well as the opportunities for more studies required on the subject.

\section{Findings \\ III. RESULT AND DISCUSSION \\ The Contexts of the Reviewed Studies}

Figure 1 shows information about the number of studies that had been reviewed in this review. It is found that there are three have been conducted to the related studies. The first one come from California, United States of America that conducted by the Arabian and also from Taipei, China also from Finland. They studied English as a Foreign Language also as a second language.

Figure 1. Writing and Listening studies conducted between 2014 to 2019

\begin{tabular}{l|l|l}
\hline America & California & 1 \\
\hline China & Taipei & 1 \\
\hline Finland & - & 1 \\
\hline
\end{tabular}

\section{The Participants in the Reviewed Studies}

Figure 2 presents the categorized participants that included in the related studies of EFL and ESL. The researcher classifies three groups. First, university students where age range between 18 to 20 [12] and the total number is 27 participants. The second, undergraduate and post-graduate students where age range between 29 to 35 [11]. The third, university students where age range between 18 to 33 . Since the study that conducted by reference [11]Saad \& Ahmed (2015) did not include the total of their participants but references [12], [13] did, researcher only classified it into three groups by their ages.

Figure 2. The classification of participants in the related studies.

\begin{tabular}{l|l}
\hline University students [12] & $\begin{array}{l}\text { Age range between 18 to } \\
20\end{array}$ \\
\hline Undergraduate and Post- & Age range between 29 to \\
graduate students [11] & 35 \\
\hline Unversity students [13] & $\begin{array}{l}\text { Age range between 18 to } \\
33\end{array}$ \\
\hline
\end{tabular}

\section{Main Aim of the Reviewed Studies}

This section of the study aims at providing a general objective of the reviewed studies. Each reviewed studies had its own objectives but the researcher only chooses of each concerning with the significant benefits of each activity. The first was to examine does daily journal writing enhance listening skill [11], the second,
[12] the benefits of keeping the listening diary,and the last, does singing enhance students' writing fluency [13].

\section{Research Methods Used in the Reviewed Studies}

The study that was carried out by reference [11] were using In-course Proficiency Test (ICPT) and Defense Language Proficiency (DLPT-5) to examine the listening comprehension skill that influence by conducting the journal writing. The terms "experimental" and "control" classes were used in the study. The participants were divided into three groups where the first two groups are in experimental classes and the other in control class. The experimental classes were introduced to journal writing activity and had assigned to do it while control class was not. The experimental classes were assigned to reflect, to give a thought and opinion toward the particular topic given.

In reference [12] study was using listening diary where students were encouraged to record all of their listening activity in their private time by following the guidelines that have been designed and prepared for students. The observation method was used in this study. In addition, the participants were also assigned to reflect, give a thought and opinion toward the activity and task given and to share what they had found during the activity into writing.

In reference [13] study, they were using teaching methods as their methodology. Prior to it, the pretest had been conducted. Then, they split up the group into three then applied the three distinguished methods on each. Singing, listening and reciting and the course included 80 hours for teaching. The instruction in the course was based on communicative approach and were included both language and culture classes. The singing group, the participants needed to sing a particular song along with gestures or movements for that song, and then the meaning of that song were discussed either before or after singing. The listening group listened to a particular song then while the song played the participants listened to it actively and paid attention to the lyrics on the handout. In other words, they only listened to the song and read the lyric that written in the handout, there were no gestures or movement included here. The last the reciting group only recited a verse that were introduced from a song, after that the meaning of the song were discussed before or after they were recited.

\section{Main Outcomes of the Reviewed Studies}

In reference [11], the study result in the improvement in listening skill of the experimental class, while reading and speaking also had been improved, it was not included in this study. This is proven by the result of the tests that had been conducted from time to time. It is found that experimental classes display a significant result due to doing journal writing rather than control class. It is believed that since "the control class did not practice any additional journal writing beyond the mandatory writing assignments" [11], their achievement did not as high as the experimental ones. The graphic will be shown figure 3 . 
In study conducted by Chen (2016) it was found that most of students who keep the listening diary consistently had enjoyed and improved in language skill. In addition, the figure 3 was provided that contain students' experiences and thoughts during keeping their listening diary.

Figure 3. The students' experiences in keeping the listening diary

Student \#1 (second diary): I really enjoy doing listening diary. It not only helps me learn vocabulary, but also helps me gain a lot of knowledge by watching English videos. I can also learn how to keep a diary and improve my English writing skills. This activity should be kept doing by students.

Students \#3 (first diary): I really enjoy doing this activity because I can learn many new things and develop vision

Students \#7 (third diary): Although this is my final diary, I won't give up listening to English regularly. I am so glad that I can finish this by myself, and it gives me a great sense of achievement. I enjoy this project very much.

Students \#10 (third diary): I feel I am getting better at listening and writing. Using English to record my learning in the diary is enjoyable.

Many students in this study as well share their thoughts of conducting the listening diary as their part of learning language. The researcher provided it into a table in figure 5.

Figure 4. The benefits from keeping listening diary

Enabling students to formulate their 12

future study plans

\begin{tabular}{l|l}
\hline Gaining new knowledge & 4 \\
\hline Improving listening skills & 3 \\
\hline Becoming more confident & 2 \\
\hline Improving English writing & 2 \\
\hline Learning new words & 2 \\
\hline Identifying learning problems & 1 \\
\hline Learning how to keep a diary & 1 \\
\hline
\end{tabular}

Within the study, it is also detected that written fluency in all both three groups were increased and have a strong effect [13]. The increasing level was on average. The measurement of fluency is determined by the words that they produced on pretest and postest within the time limit. The percentages will be shown in figure 6 .

Figure 5. The percentage fluency gain/loss

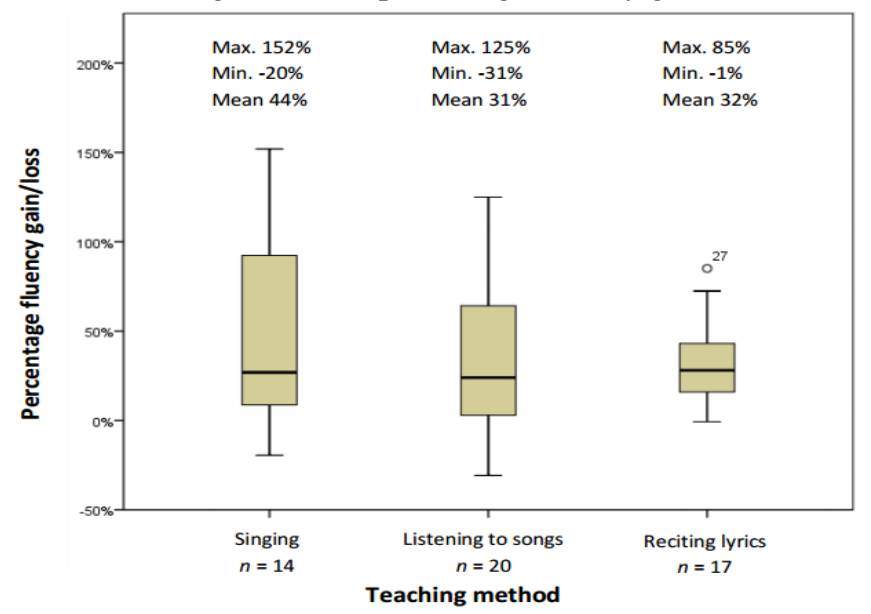

In terms of the fluency, it can be seen that its gain is significantly increased, however, there are also decreased. This occurs since the complexity of the story or verses is increased that would make the participants to take a long time to understand and to begin. It is shown in the figure 6 that written fluency in singing group increased by $44 \%$, in reciting group by $32 \%$ and listening group by $31 \%$. Based on the data, singing group were significantly increased and followed by reciting and the last listening group.

\section{Discussion and Implications}

This systematic reviewed has provided a descriptive data about integrating writing and listening skills with their relevant activities such as listening diary and journal writing and then singing. Although, the study only listed three studies regarding to the field of the study but the result had shown that integrating the two skills would enhance the other language skills which are speaking and reading as well. Learning by singing has provable increased students' fluency in writing skill as shown by the increase of scores. Despite it is truly not significant, it remains display some improvements taking place. By singing, students would enjoy learning writing material including dealing with doing $t$ pattern or grammatical structure. It can be so since they seem to learn them exclusively. Besides the benefits discussed above, it is showed that the method that combined with group discussion have provably improved students' confidence, motivation and self-esteem to share with classmates and ability to identify their strengths and weaknesses grammatically in writing along with common mistakes during conversation [11]. Further, it provides some contributions to students' academic proficiency as well to help them personally in their intellectual growth academically; students are also encouraged to develop their critical thinking, to gain more vocabulary, to improve mental clarity and thinking. In addition, this assists students to do self-study by identifying and solving problems on their own. Yet, for a reflection, what should be concerned with is the fact of the lack of the number of studies related to the integration of the writing with listening. It is a bit ironic considering its benefits in the EFL classroom activities as shown by the reviewed articles. Positively, it can serve as the broad area for future studies on that particular subject or topic. that so far only three article that related to the skill area of listening and writing skill. In sum, this review found that by integrating writing with listening activities would enhance not merely students' skill but also students' motivation in learning English. In Chen's (2016) study, it is indicated that students would establish the awareness to relevant knowledge they could attain, the different accent, new vocabularies and new expressions, not to ignore the potential of writing to exhibit the critical thinking which is of importance for academic achievement. These reviewed studies, in addition, implies the insight that the endorsement of processing information from listening activities can be an instrument to inspire productive and enjoyable writing. The 
integration of the writing with listening or vice versa apparently defines the opportunities for more researchers to design and conduct studies dealing with new strategies, method, and technique to perform the integration or facilitate the attainment of better results whether quantitatively or qualitatively or mixed ones.

\section{CONCLUSION}

In conclusion, the reviewed studies have shown that integrating writing and listening skill with particular activities within EFL or ESL classroom would have a positive influence upon students' proficiency in language learning and knowledge elaboration. These highlight the integration of the two skills bridge the development and improvement of competence required in the higher education. It polishes the skill needed for the academic achievement considering students' assignments are mostly in the forms of scientific writing as the reflection of information and knowledge processing less studies on this subject may signal the potentials for future researchers to engage with different methods and strategy for better results, breakthroughs and recommendations.

\section{REFERENCES}

[1] I. Tosuncuoğlu, 'Forming a well organized writing activities', J. Educ. Train. Stud., vol. 6, no. 6, pp. 122-127, 2018.

[2] Sabaruddin, 'Facebook Utilisation to Enhance English Writing Skill', English Lang. Teach., vol. 12, no. 8, pp. 37-43, 2019.

[3] S. E. Sulak, 'Investigation of writing habits of primary school teachers', Int. Electron. J. Elem. Educ., vol. 10, no. 4, pp. 497-504, 2018.

[4] Y. Sutarman., Sunendar, D. \& Mulyati, 'Investigating Cooperative Learning Model Based on Interpersonal Intelligence on Language Learners Skill to Write Article', Int. J. Instr., vol. 12, no. 4, pp. 201-218.
[5] F. Polatcan and N. Şahin, 'The effect of secondary school students' writing tendencies and self efficacy on writing attitudes: A structural equation modeling', J. Lang. Linguist. Stud., vol. 15, no. 2, pp. 739-753, 2019.

[6] B. Karagöz, A. Iscan, S. Baskin, and A. Irsi, 'Investigation of Turkish Teacher Candidates Listening Skills.', Univers. J. Educ. Res., vol. 5, no. 5, pp. 750-756, 2017.

[7] H. K. Keskin, G. Ari, and M. Bastug, 'Role of Prosodic Reading in Listening Comprehension.', Int. J. Educ. Lit. Stud., vol. 7, no. 1, pp. 59-65, 2019.

[8] A. P. Gilakjani and N. B. Sabouri, 'Learners' Listening Comprehension Difficulties in English Language Learning: A Literature Review.', English Lang. Teach., vol. 9, no. 6, pp. 123-133, 2016.

[9] T. Hoang, 'Teacher Self-Efficacy Research in English as a Foreign Language Contexts: A Systematic Review.', Online Submiss., vol. 15, no. 4, pp. 976-990, 2018.

[10] M. K. Aydin and M. Gürol, 'A Systematic Review of Critical Factors Regarding ICT Use in Teaching and Learning.', Int. J. Progress. Educ., vol. 15, no. 4, pp. 108-129, 2019.

[11] I. Saad and M. Ahmed, 'The Significance of Journal Writing in Improving Listening and Reading Comprehension in Modern Standard Arabic (MSA).', Univers. J. Educ. Res., vol. 3, no. 11 , pp. 815-821, 2015.

[12] C. W. Chen, 'Listening diary in the digital age: Students' material selection, listening problems, and perceived usefulness.', Jalt Call J., vol. 12, no. 2, pp. 83-101, 2016.

[13] J. Alisaari and L. M. Heikkola, 'Increasing fluency in L2 writing with singing', Stud. Second Lang. Learn. Teach., vol. 6, no. 2, 2016. 